\title{
Greenberg dysplasia (HEM) and lethal X linked dominant Conradi-Hünermann chondrodysplasia punctata (CDPX2): presentation of two cases with overlapping phenotype
}

\author{
A C Offiah, S Mansour, I Jeffrey, R Nash, N Whittock, R Pyper, S Bewley, P T Clayton, C M Hall
}

J Med Genet 2003;40:e129 (http://www.jmedgenet.com/cgi/content/full/40/12/e129)

$\mathrm{H}$ ydrops-ectopic calcification-motheaten (HEM) skeletal dysplasia is a rare lethal autosomal recessive skeletal dysplasia which is also known as Greenberg dysplasia. There are currently only seven published cases..$^{2-4} \mathrm{X}$ linked dominant chondrodysplasia punctata (Conradi-Hünermann syndrome) mainly affects females and is characterised by aberrant punctate calcification of cartilage or stippling of the epiphyses, mainly in the areas of the vertebral column, pelvis, and long bones. There is asymmetrical shortening of the long bones, patchy skin changes (follicular atrophoderma), ichthyosis, areas of alopecia, and cataracts. The severity varies from the a lethal form to a mild disease affecting adults who are sometimes diagnosed only after having an affected child. ${ }^{5}$ The variable pattern of presentation is probably related to random $\mathrm{X}$ inactivation, which may also explain the wide spectrum of severity.

We report on a further case of HEM and a lethal case of $X$ linked dominant chondrodysplasia punctata, and we highlight the similarities and differences between these two conditions, discussing the role of plasma/tissue sterol measurements in the differential diagnosis.

\section{CASE REPORTS}

\section{Case 1 (JK)}

A 32 year old Caucasian woman, gravida 2, para 0, was referred for a specialist ultrasound opinion at 14 weeks' gestation, following an earlier suspicious scan. Her partner was unrelated, 28 years old, and Caucasian. There was no relevant past or family history.

The antenatal scan demonstrated hydrops fetalis, echogenic bowel, and extreme micromelia. The pregnancy was terminated at 14 weeks and four days.

At post mortem, a marked reduction in total fetal body length was noted. This was the result of severe micromelia, as shown in fig $\mathrm{l}(\mathrm{C})$. The fetus had normal female external genitalia, but a mildly dysmorphic facies with a towering forehead, mild mandibular recession, a flattened nose, and mild hypertelorism. The thorax was small, and the abdomen protuberant as a result of significant hepatomegaly. The internal organs were otherwise unremarkable. All limbs were severely shortened, and in the upper limbs there was bilateral postaxial hexadactyly. Histological examination of the bones showed disorganisation of the growth plate, with no chondrocyte column formation but random, abrupt transition between cartilage and bone. The unossified cartilage of the femur had a rather nodular configuration, with very focal degeneration and early dusty calcification of the cartilage, not sufficient to be seen as epiphyseal stippling on $x$ ray. Sections of the upper respiratory tract confirmed the presence of patchy calcification of the cartilage of the larynx, but not of the trachea. Liver histology demonstrated large amounts of haemopoietic tissue, but this is considered normal at this

\section{Key points}

- Greenberg dysplasia and X linked dominant chondrodysplasia punctata (CDPX2: Conradi-Hünermann) are both rare skeletal dysplasias. This report demonstrates the similarity of the radiological features in the lethal form of CDPX2 with those seen in Greenberg dysplasia, particularly in the distribution of ectopic calcification.

- The radiological and clinical similarities can be explained by the fact that both conditions are due to different abnormalities in the cholesterol biosynthesis pathway.

- Careful sterol analysis may help in the differential diagnosis of these two conditions. Mutation analysis of the causative genes can confirm the diagnosis, allowing accurate recurrence risks to be given to the parents.

gestation. A few portal tracts showed slight portal fibrosis, but there were no other significant histological abnormalities.

Radiological abnormalities were striking, and included a motheaten appearance of extremely shortened long bones, and significant platyspondyly with poorly developed vertebral bodies. The thorax was narrow with short, beaded ribs. In addition there was ectopic calcification of the costal cartilage (hook-like projections), the laryngeal cartilages, and the pelvis. The skull was poorly ossified.

\section{Case 2 (LB)}

A 25 year old Caucasian mother, gravida 2, para 0, presented at 15 weeks and two days for a routine ultrasound scan. She had had a previous miscarriage at eight to 10 weeks of gestation, for which post mortem results were not available. Her Caucasian, unrelated partner was also 25 years of age. There was no relevant past or family history.

The ultrasound scan demonstrated a small fetus (crownrump length of $83.5 \mathrm{~mm}$ consistent with a gestational age of 13 weeks), nuchal oedema (nuchal translucency $8.8 \mathrm{~mm}$ ), what appeared to be multiple fractures of very short long bones, and a narrow thorax. A diagnosis of a lethal dysplasia was suggested, and the pregnancy was terminated following discussion with the parents.

Abbreviations: HEM, hydrops-ectopic calcification-motheaten; GC-MS, gas chromatography-mass spectrometry; PCR, polymerase chain reaction 
At post mortem, the foot length, head circumference, and other measured parameters were all on the third to 10th centile, consistent with a gestational age of 14 weeks. Body weight, however, was below the third centile for 14 weeks. The fetus had normal female external genitalia, a normal facies, a narrow thorax, and a swollen, rounded abdomen, as evident in fig 2 (C). Apart from hepatomegaly the internal organs were normal. There was asymmetrical long bone shortening, with the right upper and lower limbs being longer than the left, asymmetrical limb deformities with bowing, and left talipes, but neither polydactyly nor syndactyly. The umbilical cord vessels were normal. Bone histology revealed poorly formed chondrocytic columns at the growth plate, which were undergoing somewhat irregular ossification. However, the subarticular cartilage had several small areas of partly cystic degeneration, bordered by cartilage showing fine calcification. Coarse, granular calcification (similar to that in case 1) was seen in the laryngeal cartilage. The liver histology was normal apart from rather prominent extramedullary haematopoiesis.

Radiological abnormalities included less marked shortening of the long bones (predominantly rhizomelic) with better bone modelling than case 1, significant platyspondyly, a narrow misshapen chest, and short beaded ribs, again with ectopic calcification of the costal cartilages. There was stippling of the epiphyses, calcification of the laryngeal cartilage, and an area of ectopic calcification of the left pelvis which was very similar to that seen in case 1 . The skull was very poorly ossified.
The mother became pregnant again but unfortunately developed acute myeloid leukaemia at 12 weeks' gestation, and had a termination of pregnancy in order to start chemotherapy.

\section{INVESTIGATIONS}

Analysis of sterols by gas chromatography-mass spectrometry (GC-MS) was carried out as described previously on tissue samples from both fetuses. ${ }^{67}$ The GC-MS was operated both in scan mode to obtain full spectra of unusual sterols, and in selected ion monitoring mode to enable quantification of coeluting sterols. The following ions were used: cholestanol m/z 306, 8(9)-cholestenol and lathosterol, $\mathrm{m} / \mathrm{z} 458 ; 7$-dehydrocholesterol and 8-dehydrocholesterol, m/z 325; desmosterol, $\mathrm{m} / \mathrm{z}$ 372; lanosterol, $\mathrm{m} / \mathrm{z} 393$; and 8,14-cholestadien-3 $\beta$-ol, $\mathrm{m} / \mathrm{z} 182$.

Following informed consent, genomic DNA from case 2 was extracted from fetal tissue using standard methods, and exons 2-5 of the human EBP gene were directly amplified. Specifically, exon 5 was amplified using primers EBP 5F $5^{\prime}$ CAG AAT ACT TAG CTC TGA GAC C-3' and EBP 5R 5'-GGA TCT CTC AGT GTT AGA GTC-3'. The polymerase chain reaction (PCR) products were examined by $2 \%$ agarose gel electrophoresis, purified, and directly sequenced on an ABI 377 genetic analyser (ABI, Foster City, USA).

\section{RESULTS}

Results of biochemical studies and karyotype analysis are shown in table 1 .
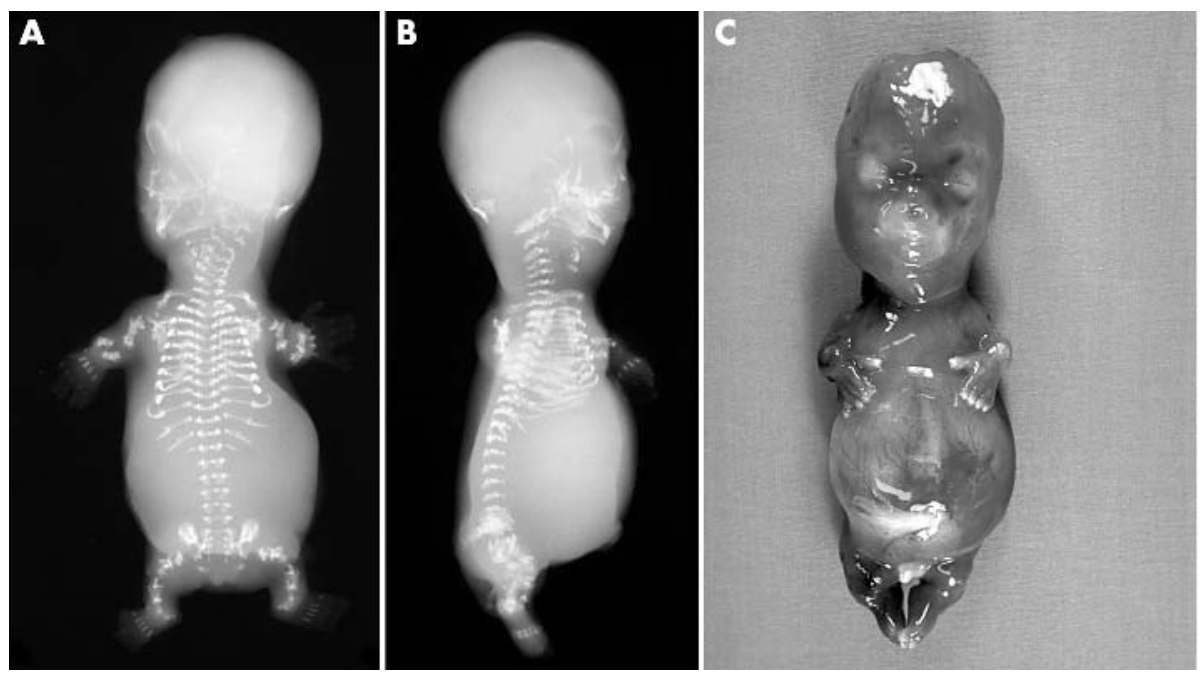

Figure 1 (A) anteroposterior and (B) lateral radiographs of case 1 at 15 weeks'gestation. Note ectopic calcification/ossification, marked rhizomelia, postaxial polydactyly, motheaten appearance with multiple "fractures", defective skull ossification, platyspondyly, protruberant abdomen, and small thorax. (C) Photograph of fetus with Greenberg dysplasia.
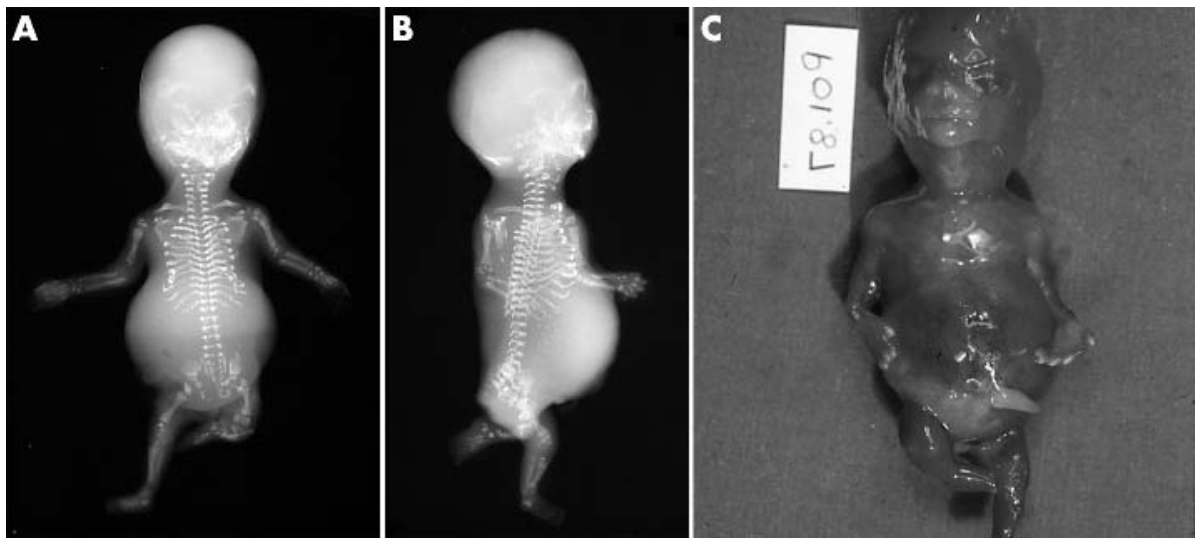

Figure 2 (A) anteroposterior and (B) lateral radiographs of case 2 at 14 weeks' gestation. Note ectopic calcification/ossification, multiple "fractures", defective skull ossification, platyspondyly, protuberant abdomen (hepatomegaly), and small thorax. (C) Photograph of fetus with lethal X-linked dominant chondrodysplasia punctata (Conradi-Hünermann syndrome). 
Table 1 Results of laboratory tests

$\begin{array}{llll}\text { Test } & \text { Case 1 } & \text { Case 2 } & \text { Controls } \\ \text { Karyotype } & 46 \mathrm{XX} & 46 \mathrm{XX} & - \\ \text { Cholestanol } & 0.63 & 2.00 & \text { Not measured } \\ \text { 8-dehydrocholesterol } & <0.3 & 0.64 & <0.3 \\ \text { 8,14 -cholestadien-3 } \beta \text {-ol } & 13 & 0 & <0.1 \\ \text { 8(9)-cholestenol } & 0 & 5.88 & <1.0 \\ \text { 7-dehydrocholesterol } & 0.36 & 0.06 & 0.1-0.3 \\ \text { Desmosterol } & 1.46 & 2.94 & 0.5-3.0 \\ \text { Lathosterol } & 5.78 & 6.37 & 1-20 \\ \text { Lanosterol } & 0.38 & 0.20 & 0.09-0.8\end{array}$

The sterol contents of muscle tissue from the two fetuses is expressed as a ratio to cholesterol $(\mu \mathrm{mol} / \mathrm{mmol})$.

TIC: $02012911 . \mathrm{D}$

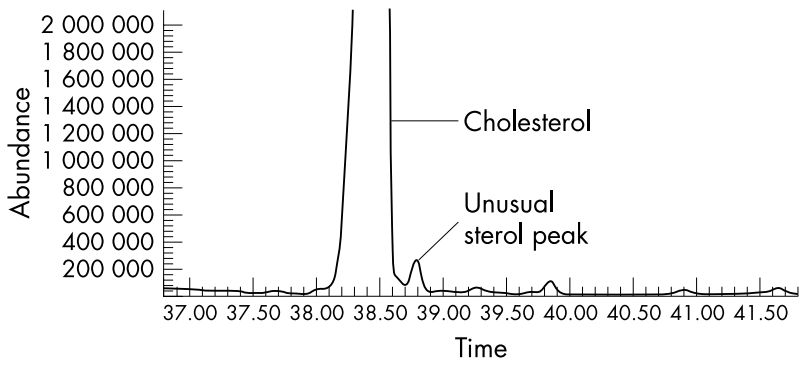

Figure 3 Total ion current obtained by GC-MS analysis of sterols from case 1. The second largest peak elutes just after cholesterol. The total ion current looked similar for case 2; however, mass spectrometry indicated that the unusual peak had a different identity in the two cases.

\section{Case 1}

Analysis of muscle tissue revealed that the largest peak after cholesterol had a mass spectrum which matched a spectrum in the literature of 8,14-cholestadien-3 $\beta$-ol, ${ }^{7}$ shown in figs 3 and $4(\mathrm{~A})$. This abnormality had previously been described in $\mathrm{HEM}^{9}$ and therefore confirmed the diagnosis in this fetus.

\section{Case 2}

Analysis of muscle tissue revealed that the largest sterol peak after cholesterol had a spectrum matching that of 8(9)cholestenol, shown in fig 4 (B). Quantitative analysis revealed that the ratios $8(9)$-cholestenol/cholesterol and 8dehydrocholesterol/cholesterol were substantially elevated (table 1). These findings were consistent with a diagnosis of $3 \beta$-hydroxysterol $\Delta^{8}$ - $\Delta^{7}$-isomerase deficiency and therefore confirmed a diagnosis of $\mathrm{X}$ linked dominant chondrodysplasia punctata (Conradi-Hünermann $\left(\right.$ CDPX2)). ${ }^{10}$ Direct sequencing of exon 5 of the EBP gene revealed a novel heterozygous substitution, designated $552 \mathrm{C}>\mathrm{G}$. This converts tyrosine 184 to a stop codon, Y184X, within the fourth transmembrane domain of the protein, and is predicted to result in a truncated/non-functional protein.

\section{DISCUSSION}

The radiological findings in these two fetuses were strikingly similar despite being clearly distinct conditions. Both fetuses had hook-like ectopic calcification of the ribs, a calcified ring on the inferior pubic rami, calcification of the larynx, marked platyspondyly, and a poorly mineralised skull. Case 2 was at
Scan 1994 (38.791 min): $02012911 . D$
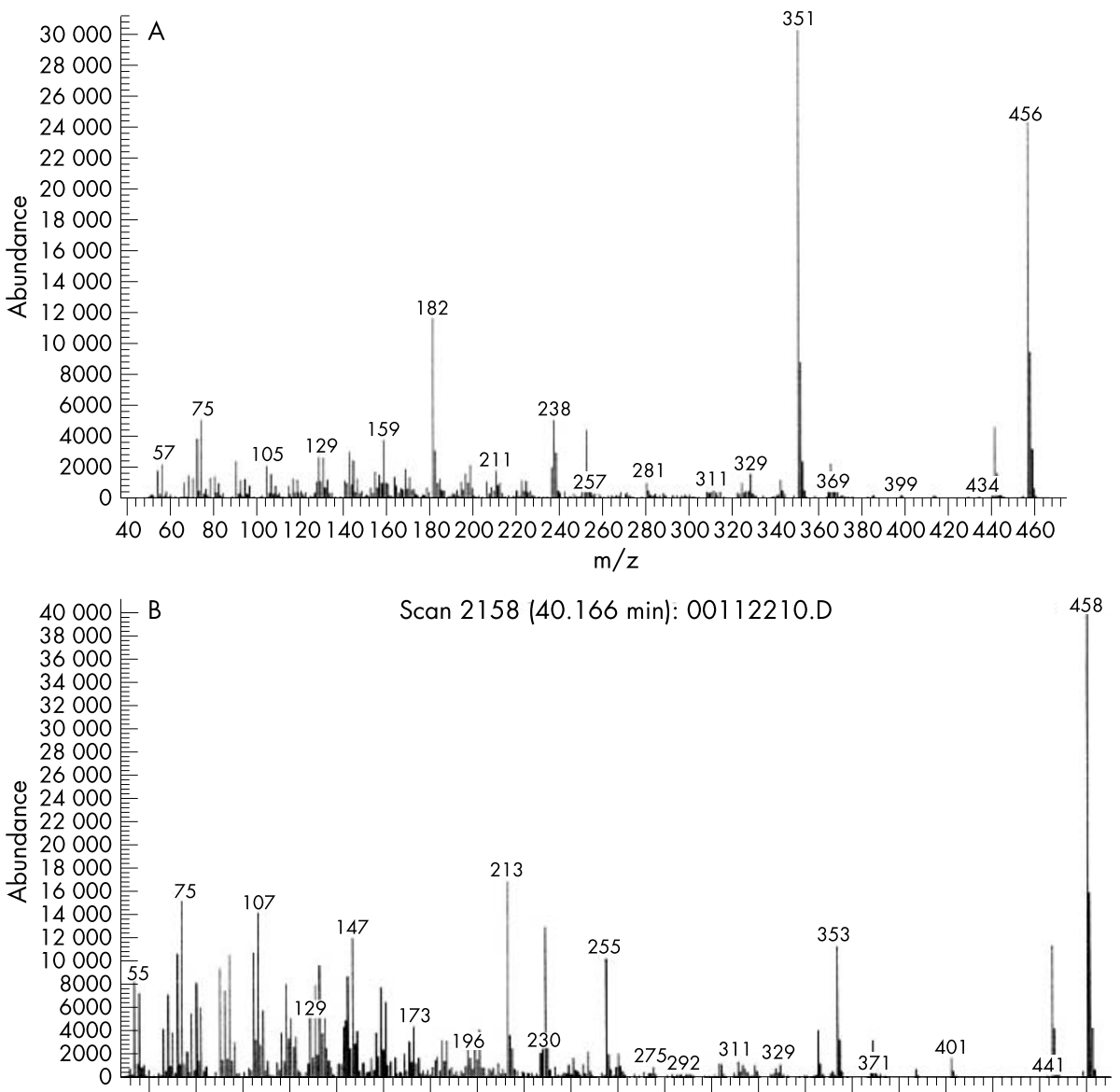

6080100120140160180200220240260280300320340360380400420440460 $\mathrm{m} / \mathrm{z}$
Figure 4 Mass spectra of the unusual peaks in muscle tissue from $(A)$, case 1 , and (B), case 2 . Comparison of the mass spectra with a reference compound or a spectrum in the literature provided peak identities of 8,14-cholestadien-3 $\beta$-ol and 8(9)cholestenol for (A) and (B), respectively. 
the severe end of the Conradi- Hünermann spectrum, which would have been lethal in this case. Most cases of ConradiHünermann syndrome (CDPX2) present in childhood, and do not have such marked skeletal changes; there is usually, therefore, no diagnostic confusion with Greenberg dysplasia.

HEM or Greenberg dysplasia is now the sixth condition that has been shown to be associated with an inherited abnormality of cholesterol biosynthesis (fig 5). ${ }^{9}$ The first condition, Smith-Lemli-Opitz syndrome, was shown to be due to a deficiency of $3 \beta$ hydroxysterol $\Delta^{7}$ reductase. This results in an increase of the immediate precursor, 7dehydrocholesterol, and a relative deficiency of cholesterol. It is characterised by multiple congenital abnormalities, including holoprosencephaly and severe learning difficulties. It was noted that some affected individuals had stippling of the epiphyses. Two other, similar, autosomal recessive conditions were found to be due to enzyme deficiencies in the pathway(s) from lanosterol to cholesterol-that is, desmosterolosis ( $3 \beta$-hydroxysterol $\Delta^{24}$-reductase deficiency) ${ }^{7}$ and lathosterolosis ( $3 \beta$-hydroxysterol $\Delta^{5}$-desaturase deficiency). In addition, two $\mathrm{X}$ linked dominant conditions have similarities to each other, and are due to deficiencies of enzymes in the sterol pathway, namely Conradi-Hünermann syndrome (sterol $\Delta^{8}-\Delta^{7}$ isomerase deficiency) $)^{10}$ and CHILD syndrome (sterol C4-demethylase deficiency). ${ }^{9}$ Presumably these enzyme deficiencies would be lethal in the recessive form, as they are at an early stage of the pathway; but
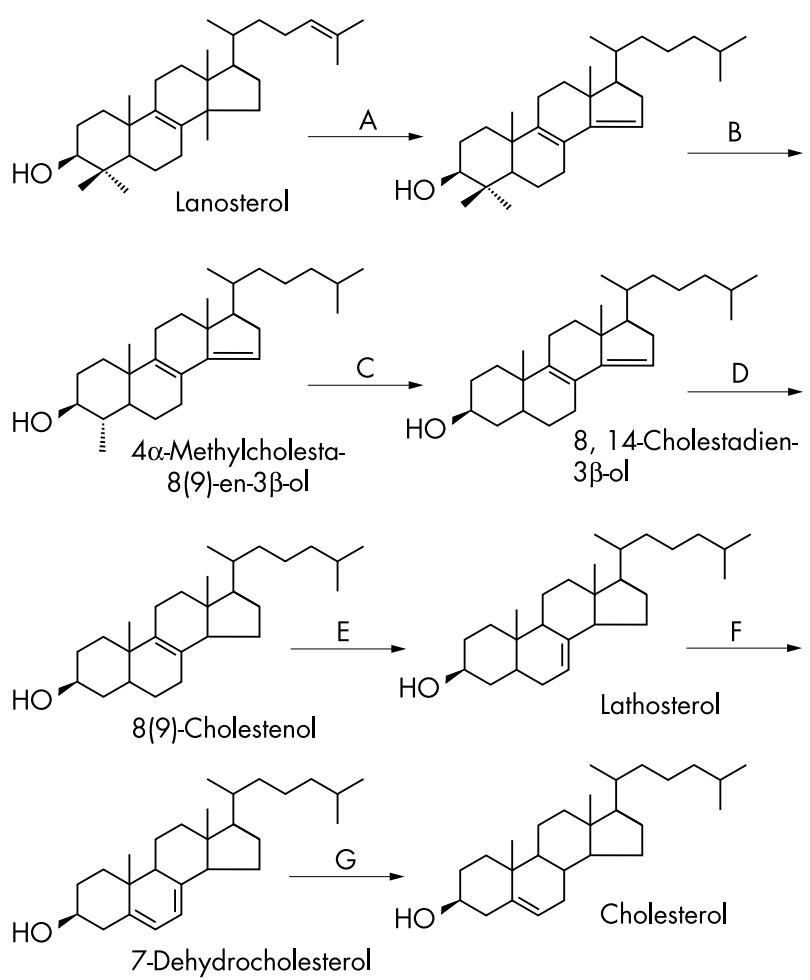

Figure 5 Simplified representation of one of the major pathways from lanosterol to cholesterol, showing intermediates, enzymes, and sites of inborn errors. The reactions catalysed by enzymes can occur in a different sequence so that-for example-saturation of the C24-C25 double bond is the last step instead of being the first or second. (A), lanosterol demethylase; (B), 3 $\beta$-hydroxysteroid $\Delta^{24}$-reductase (defective in desmosterolosis); (C), $4 \alpha$-methylsterol-4-demethylase complex (defective in CHILD syndrome); (D), 3 $\beta$-hydroxysteroid $\Delta^{14}$-reductase (defective in HEM/Greenberg dysplasia); (E), 3 $\beta$-hydroxysteroid $\Delta^{8}-\Delta^{7}$-isomerase (defective in Conradi-Hünermann syndrome); (F), $3 \beta$-hydroxysteroid $\Delta^{5}$-dehydrogenase or lathosterol dehydrogenase (defective in lathosterolosis); (G), 7-dehydrocholesterol reductase (defective in Smith-Lemli-Opitz syndrome). because of $\mathrm{X}$ inactivation the abnormality is not expressed in every cell, and there is compensation by the normal allele.

All of these conditions involve the skeleton, and a common finding is stippling of the epiphyses. The presence of ectopic calcification in HEM led to the identification of a deficiency of another enzyme in this pathway, sterol- $\Delta^{14}$-reductase, resulting in an increase in 8,14 -cholestadien-3 $\beta$-ol. ${ }^{9}$ Another report demonstrated overlap between HEM and SmithLemli-Opitz syndrome (HEM with additional non-skeletal abnormalities, including intestinal malrotation and hypolobated lungs, features which are more commonly associated with SLO). ${ }^{3}$ The similarities suggest that the malformations are directly related to the sterol aberrations and not to any other function of these genes. It is not clear whether the abnormalities are due to a relative deficiency of cholesterol or possibly the build up of toxic precursors.

It has been previously shown that defects in cholesterol biosynthesis can result in marked developmental defects in vertebrate embryos. Rats treated with cholesterol biosynthesis inhibitors in early pregnancy developed a number of birth defects, including variable manifestations of holoprosencephaly. ${ }^{11}$ The teratogenic effects of these inhibitors can be blocked by a hypercholesterolaemic diet. Holoprosencephaly is also seen in embryos lacking the Sonic Hedgehog gene. ${ }^{12}$ There is now evidence that cholesterol plays a direct role in the Hedgehog signalling pathway. The Hedgehog proteins are a family of signalling molecules that are essential in embryogenesis. The activity of these molecules is dependent on an autocleavage reaction that results in a lipid-modified amino-terminal fragment. This lipid has been shown to be cholesterol. ${ }^{11}$ Indian Hedgehog is a member of this family of proteins and therefore requires cholesterol to become active. This particular gene is important in the development of cartilage and bone. It is possible that the skeletal abnormalities seen in the two conditions presented here may be due to abnormalities in the Indian Hedgehog signalling pathway. ${ }^{13}$

The underlying abnormality in the sterol pathway in Xlinked dominant Conradi-Hünermann syndrome ${ }^{10}$ has led to the identification of the gene known as the Emopamil binding protein, $E B P .{ }^{14}{ }^{15}$ This gene is located on chromosome Xpl1.22 to Xpl1.23, and was found to be a sterol $\Delta^{8}-\Delta^{7}$ isomerase, and mutations have now been identified in a number of patients with CDPX2.

The finding of a particular sterol abnormality in HEM has led to the identification of the gene for this condition, ${ }^{17}$ lamin $\mathrm{B}$ receptor; heterozygous mutations were originally identified in families with a benign, altered nuclear morphology in granulocytes (Pelger-Huët anomaly). ${ }^{16}$ This gene was discovered to have sterol reductase activity, and was therefore a good candidate for Greenberg dysplasia. In the recent paper by Waterham et $a{ }^{17}$ a homozygous 1599-1605TCTTCTA to CTAGAAG substitution was found in the lamin B receptor gene in a single case of Greenberg dysplasia.

The sterol pathway is clearly extremely important during the early stages of development, and abnormalities in this pathway may account for other congenital malformations. Sterol profile analysis is a useful diagnostic tool, particularly in the lethal chondrodysplasias. This is a commonly available analysis, as opposed to the less available mutation analysis of the genes encoding the various enzymes involved in the cholesterol pathway.

\footnotetext{
Authors' affiliations

A C Offiah, C M Hall, Department of Radiology, Great Ormond Street Hospital for Children, London, UK

S Mansour, I Jeffrey, R Nash, SW Thames Regional Genetics Service and Department of Perinatal Pathology, St George's Hospital Medical School, London, UK
} 
N Whittock, Institute of Biomedical and Clinical Science, Peninsula Medical School, Exeter, UK

R Pyper, Department of Obstetrics and Gynaecology, Worthing Hospital, Sussex, UK

S Bewley, Department of Fetal Medicine, St Thomas's Hospital, London, UK

P T Clayton, Biochemistry Endocrinology and Metabolism Unit, Institute of Child Health, London, UK

Correspondence to: Dr Sahar Mansour, SW Thames Regional Genetics Service, St George's Hospital Medical School, London SW17 ORE, UK; smansour@sghms.ac.uk

\section{REFERENCES}

1 Greenberg CR, Rimoin D, Gruber HE, et al. A new autosomal recessive lethal chondrodysplasia with congenital hydrops. Am J Med Genet 1988;29:623-32.

2 Chitayat D, Gruber H, Mullen BJ, et al. Hydrops - ectopic calcification motheaten skeletal dysplasia (Greenberg dysplasia): prenatal diagnosis and further delineation of a rare genetic disorder. Am J Med Genet 1993;47:272-7.

3 Horn L-C, Faber R, Meiner A, et al. Greenberg dysplasia: first reported case with additional non-skeletal malformations and without consanguinity. Prenat Diagn 2000;20:1008-11.

4 Trajkovski Z, Vrcakovski M, Saveski J, et al. Greenberg dysplasia (hydrops ectopic calcification - motheaten skeletal dysplasia): prenatal ultrasound diagnosis and review of the literature. Am J Med Genet 2002;1 11(4):415-19.

5 Pryde PG, Bawle E, Brandt F, et al. Prenatal diagnosis of nonrhizomelic chondrodysplasia punctata (Conradi-Hünermann syndrome). Am J Med Genet 1993;47:426-31
6 Clayton PT, Bowron A, Mills KA, et al. Phytosterolaemia in children with parenteral nutrition-associated cholestatic liver disease. Gastroenterology 1993; 105:1806-13

7 FitzPatrick DR, Keeling JW, Evans MJ, et al. Clinical phenotype of desmosterolosis. Am J Med Genet 1998:75:145-52.

8 Gerst N, Ruan B, Pang J, et al. An updated look at the analysis of unsaturated C27 sterols by gas chromatography and mass spectrometry. J Lipid Res 1997;38:1685-701.

9 Kelley RI. Inborn errors of cholesterol biosynthesis. In: Barness LA, eds. Advances in Pediatrics. Vol 47. St Louis, MO, USA: Mosby, 2002:1-53.

10 Kelley RI, Wilcox WG, Smith M, et al. Abnormal sterol metabolism in patients with Conradi- Hünermann-Happle syndrome and sporadic chondrodysplasia punctata. Am J Med Genet 1999;83:213-19.

11 Porter JA, Young KE, Beachy PA. Cholesterol modification of Hedgehog signaling proteins in animal development. Science 1996;274:255-9.

12 Roessler E, Belloni E, Gaudenz K, et al. Mutations in the Sonic Hedgehog gene cause holoprosencephaly. Nat Genet 1996;14:357-60.

13 Kobayashi T, Chung UI, Schipani E, et al. PTHrP and Indian Hedgehog control differentiation of growth plate chondrocytes at multiple steps. Dev 2002; 129:2977-86

14 Derry JMJ, Gormally E, Means GD, et al. Mutations in a $\Delta^{8}-\Delta^{7}$ sterol isomerase in the tattered mouse and $\mathrm{X}$-linked chondrodysplasia punctata. Nat Genet 1999;22:286-90.

15 Braverman N, Lin P, Moebius FF, et al. Mutations in the gene encoding 3bhydroxysteroid- $\Delta^{8}, \Delta^{7}$-isomerase cause X-linked dominant ConradiHünermann syndrome. Nat Genet 1999;22:291-4.

16 Hoffmann Katrin, Dreger CK, Olins AL, et al. Mutations in the gene encoding the lamin $B$ receptor produce an altered nuclear morphology in granulocytes (Pelger-Huet anomaly). Nat Genet 2002;31:410-14

17 Waterham HR, Koster J, Mooyer $\mathrm{P}$, et al. Autosomal recessive HEM/ Greenberg skeletal dysplasia is caused by $3 \Delta$-hydroxysterol $\Delta^{14}$-reductase deficiency due to mutations in the lamin B receptor gene. Am J Hum Genet 2003;72:1013-17. 